\begin{tabular}{|c|c|}
\hline Title & $\begin{array}{l}\text { Cost Effectiveness of Drive and Retrieve System in Hokkaido for A cute I schemic Stroke Patient Treatment U sing } \\
\text { Geographic Information System }\end{array}$ \\
\hline Author(s) & $\begin{array}{l}\text { Morii, Y asuhiro; Osanai, Toshiya; Ishikawa, Tomoki; Fujiwara, Kensuke; Tanikawa, Takumi; Houkin, Kiyohiro; } \\
\text { Kobay ashi, Eiichi; Ogasawara, Katsuhiko }\end{array}$ \\
\hline Citation & $\begin{array}{l}\text { Journal of stroke \& cerebrovascular diseases, 28(8), 2292-2301 } \\
\text { https://doi.org/10.1016/.jstrokecerebrovasdis.2019.05.020 }\end{array}$ \\
\hline Issue Date & 2019-08 \\
\hline Doc URL & http:/hdl .handle.net/2115/79156 \\
\hline Rights & $\begin{array}{l}\text { () 2019. This manuscript version is made available under the CC-BY-NC-ND } 4.0 \text { license } \\
\text { http://creativecommons.org/icenses/oy-nc-nd/4.0/ }\end{array}$ \\
\hline Rights(URL) & https://creativecommons.org/icenses/by-nc-nd/4.0/ \\
\hline Type & article (author version) \\
\hline File Information & Morii2019.pdf \\
\hline
\end{tabular}

Instructions for use 
A Cost-effectiveness Simulation of Drive and Retrieve System in Hokkaido

\title{
Cost effectiveness of Drive and Retrieve System in Hokkaido for Acute Ischemic Stroke Patient Treatment Using GIS
}

\author{
Yasuhiro Morii ${ }^{1}$ MHS, Toshiya Osanai ${ }^{2}$,PhD,MD, Tomoki Ishikawa ${ }^{3}$ MHS, MBA, Kensuke Fujiwara ${ }^{4}, \mathrm{PhD}$, \\ Takumi Tanikawa ${ }^{5}$ PhD, Kiyohiro Houkin ${ }^{2}$ PhD,MD, Eiichi Kobayashi ${ }^{1}$ BS, Katsuhiko Ogasawara ${ }^{4 *}$, PhD,
} MBA

1 Graduate School of Health Sciences, Hokkaido University, Sapporo, Hokkaido, Japan

2 Department of Neurosurgery, Graduate School of Medicine, Hokkaido University, Sapporo, Hokkaido, Japan

3 Institute for Health Policy and Economy, Minato-ku, Tokyo, Japan

4. Faculty of Health Sciences, Hokkaido University, Sapporo, Hokkaido, Japan.

5 Faculty of Health Sciences, Hokkaido University of Science, Sapporo, Hokkaido, Japan

Corresponding Author*

Email: oga@hs.hokudai.ac.jp

Tel: 011-706-3409

Affiliation : Faculty of Health Sciences, Hokkaido University, Sapporo, Hokkaido, Japan.

Address: Kita 12 Nishi 5, Kita-ku, Sapporo, Hokkaido, Japan

Cover title: Cost effectiveness of Drive and Retrieve System

Key words: Cost-Effectiveness, Geographic Information System, Ischemic Stroke, Endovascular

Thrombectomy, Drive and Retrive System 
A Cost-effectiveness Simulation of Drive and Retrieve System in Hokkaido

\section{Abstract}

Background and Purpose: Although endovascular thrombectomy combined with recombinant tissue-type plasminogen activator is effective for treatment of acute ischemic stroke, regional disparities in implementation rates of those treatments have been reported. Drive and retrieve system, where a qualified neurointerventionist travels to another primary stroke center for endovascular thrombectomy, has been practiced in parts of Hokkaido, Japan. This study aims to simulate he cost-effectiveness of the drive and retrieve system, which can be a method to enhance equality and cost-effective of treatments for acute ischemic stroke.

Materials and methods: The number of patients who had acute ischemic stroke in 2015 is estimated. Those patients are generated according to the population distribution, and thereafter patient transport time is analyzed in the three scenarios (1) 60-minute drive scenario, (2) 90-minute drive scenario, in which the drive and retrieve system operates within 60-minute or 90-minute driving distance (3) without the system, using geographic information system. Incremental cost-effectiveness rate, quality adjusted life years, and medical and nursing care costs are estimated from the analyzed transport time.

Findings: The incremental cost-effectiveness rate by implementing the system was dominant. Cost reduction of $\$ 213,190$ and $\$ 247,274$ was expected in 60-minute and 90-minute drive scenario, respectively. Such benefits are the most significant in Soya, Emmon, Rumoi, and Kamikawahokubu medical areas.

Conclusion: The drive and retrieve system could enhance regional equality and cost effectiveness of ischemic stroke treatments in Hokkaido, which can be achieved using existing resources. Further studies are 
A Cost-effectiveness Simulation of Drive and Retrieve System in Hokkaido

required to clarify its cost-effectiveness from hospital perspective. 
A Cost-effectiveness Simulation of Drive and Retrieve System in Hokkaido

\section{Introduction}

Stroke is the fourth largest cause of death in Japan, and accounts for the largest proportion of patients with nursing care needs [1]. Approximately 26.9\% of patients with nursing care needs in Japan have had stroke [2]. In the aging society of Japan, where medical and nursing care costs have been increasing, the viewpoint of cost-effectiveness of stroke treatments needs to be considered. The stroke databank (2016) reported that ischemic stroke accounted for $68.7 \%$ of all types of strokes [3]. Therefore, it is necessary to consider costeffective management of ischemic stroke treatments.

Recombinant tissue-type plasminogen activator (rt-PA) and endovascular thrombectomy have been known as effective treatments of acute ischemic stroke (AIS) [4,5]. Several randomized controlled trials (RCTs) and meta-analysis have reported the effectiveness of these treatments [6-8]. Despite the efficacy, disparity in implementation rates of the treatments between rural areas and urban areas have been reported due to their time limits [9, 10]. Furthermore, the later the reperfusion is performed, the worse the outcome will be [11]. Therefore, efforts should be made to shorten the processing time between symptom onset and treatment. Hokkaido, a prefecture in Japan, has the largest land area a with lowest population density. Moreover, Hokkaido has the highest number of secondary medical areas among all the prefectures in Japan [12], which are regional units that provide in-hospital medical services, including stroke care. Disparities in medical services [13] and stroke treatments $[14,15]$ have been reported in Hokkaido. Although it is desirable that stroke care is provided equally in all medical areas, it is not always possible due to lacking medical resources such as Computed Tomography, Magnetic Resonance Imaging, electrocardiogram, and qualified 
A Cost-effectiveness Simulation of Drive and Retrieve System in Hokkaido

neurointerventionists for endovascular thrombectomy. Therefore, a system for medical cooperaten that specializes in endovascular treatment for AIS is needed to ensure prompt initiation of treatment and to reduce the time from onset to reperfusion. Many such systems have been proposed till date. For example, some studies have evaluated the "drip and ship method" [16], whereas others have reported better results with centralized direct transport, or the "mothership" method, because of its reduced transportation time and potential reduction in mortality rate [17]. Several studies have proposed the "drive and retrieve system," where neurointerventionists, who work at comprehensive stroke centers, travel to primary stroke centers to provide endovascular thrombectomy. By implementing the drive and retrieve system, more patients will be eligible for these treatments, and better outcomes can be expected due to earlier treatment initiation [18]. To provide data to achieve equal and efficient treatments of patients with AIS, this study simulates the effect of the drive and retrieve system on accessibility to rt-PA and endovascular thrombectomy, and assesses the cost effectiveness of drive and retrieve system from the perspective of medical and nursing care expenditures.

\section{Materials and Methods}

\section{Subjects and outcomes}

The subjects in this study are a virtual cohort of patients with AIS in Hokkaido in 2015 (for population distribution and secondary medical areas in Hokkaido, refer to Fujiwara et al. (2017) [15]). The analysis period is 3 years from the patients' onsets. Solitary island areas are excluded in the analysis. Three scenarios, with (1) 60-minute and (2) 90-minute drive and retrieve systems (60-minute scenario and 90-minute scenario) where qualified neurointerventionists travel to primary stroke centers for endovascular 
A Cost-effectiveness Simulation of Drive and Retrieve System in Hokkaido

thrombectomy within 60 minute or 90 minute drive distance (Spoke hospitals) after patients' onsets, and (3)

without the system (the current scenario) are compared and cost effectiveness achieved by implementing the drive and retrieve system is assessed. The primary outcome is incremental cost-effectiveness rate (ICER), which is calculated by dividing incremental costs with incremental Quality-adjusted life years (QALY). ICER is the standard measurement for cost effectiveness at the National Institute of Health and Care Excellence in Britain [19], Japan [20], and elsewhere. In this study, ICER is evaluated by the 5,000,000 JPY-per-QALY threshold (approximately 44, 228\$), which is suggested by Ministry of Health, Labour, and Wealth for evaluating cost effectiveness in Japan [21]. Cost gain (reduction) by the system is also analyzed. The costs include medical costs and nursing costs up to 3 years after symptom onset, and the gained QALYs are estimated for the same period. Per-time costs of the Drive and retrieve system are also calculated for each secondary medical area by dividing the incremental cost by the number of patients whose transport time is shorten. Data on the 29 hospital where neurointerventionists are present (Hub hospitals) and on 108 spoke hospitals (without neurointerventionists but equipped for the treatment) is obtained from the websites of The Japanese Society for Neuroendovascular Therapy [22] and Hokkaido Medical Plan [13], respectively.

\section{Patient generation}

First, we estimate the number of stroke patients from the incidence data of Patient Survey from the Ministry

of Health, Labor and Welfare, and the population (2014) [22]. Then the number of ischemic stroke patients is estimated using data from the Stroke databank, a Japanese nationwide database of stroke patients in Japan [3]. Thereafter, the number of patients is randomly allocated to each $1 \mathrm{~km}^{2}$ mesh of the geographic 
A Cost-effectiveness Simulation of Drive and Retrieve System in Hokkaido

information system (GIS), in accordance with its population. This allocation is repeated 10,000 times, and the average number for each mesh is used as the number of patients who are generated on ArcGIS Desktop10

(ESRI Inc.) using random point generation.

\section{Transport time analysis}

Transport time is analyzed using closest facility analysis of GIS. The sum of the time when an ambulance arrives at a patient location and the time of arrival from the patient location to a hospital is defined as transport time. Ambulance locations are obtained from National Land Numerical Information (2015) [23]. To assess the transport time in 60-minute and 90-minute scenarios, the 76 spoke hospitals which are within 60-minute driving distance from the 29 hospitals where neurointerventionists work (Hub hospitals) are identified using "object identifier matrix" function of GIS. Likewise, the 84 spoke hospitals within 90minute driving distance from the hub hospitals are identified. The transport time in each of the 3 scenarios is then analyzed. Patients are divided into 4 groups depending on the following time windows: (1) those transported within 1 hour (2) those transported between 1-2 hours (3) those transported between 2-3 hours, and (4) those transported more than 3 hours after symptom onset.

\section{Patient outcome estimation}

The drive and retrieve system aims to provide early rt-PA and endovascular thrombectomy for as many patients as possible. Our analysis attempts to study the outcomes that patients gain through earlier reperfusion, by using data from the Highly Effective Reperfusion evaluated in Multiple Endovascular Stroke Trials (HERMES) collaboraten study [24], a meta-analysis of 5 RCTs [25-29]. In the HERMES study, rt- 
PA was used for more than $83 \%$ of the patients treated with endovascular thrombectomy [24]. Furthermore, the guideline for using mechanical thrombectomy device in Japan (2015) stated that rt-PA should be given the first priority [5]. These 2 treatments should be comprehensively considered. Therefore, it is assumed that endovascular thrombectomy is implemented after rt-PA treatment. In this study, rt-PA time window (4.5 hours) is used for patient severity estimate [30]. Although the time limit is 4.5 hours after symptom onset, Spokoyny et al. (2015) reported that onset time tended to be estimated around 30 minutes earlier than the actual onset time [31]. In addition, the Japan Stroke Society (2015) recommends that rt-PA be administrated within 1 hour after door time [4]. Considering the uncertainty in onset time [31] and the time until rt-PA administraten [4], it is assumed that patients whose transport time is within 3 hours after symptom onset are eligible for rt-PA, and subsequently endovascular thrombectomy. According to a report from Japan Stroke Association, it is assumed that rt-PA and endovascular thrombectomy implementation rates are $16.9 \%$ for those transported within three hours [32].

For severity estimation, modified Rankin Scale (mRS) at 90 days after symptom onset is used. The data on reperfusion time and mRS at 90 days are obtained from the HERMES study (Table1) [11]. According to the transport time groups, the patients are given the expected mRS stage distributions (Table 1). It is assumed that the patient severity distributions will not change during the study period.

Table1. Expected mRS distribution at 3 months after onset [11]

\begin{tabular}{|c|c|r|r|r|r|r|r|r|}
\hline \multirow{2}{*}{$\begin{array}{c}\text { eligibility for rt-PA } \\
\text { and endovascular } \\
\text { thrombectomy }\end{array}$} & time window & \multicolumn{6}{|c|}{ Rates of patients at each mRS stage (\%) } \\
\cline { 3 - 9 } & & 0 & 1 & 2 & 3 & 4 & 5 & 6 \\
\hline
\end{tabular}


A Cost-effectiveness Simulation of Drive and Retrieve System in Hokkaido

\begin{tabular}{|c|c|c|c|c|c|c|c|c|}
\hline eligeble & $\begin{array}{c}\text { transported } \\
\text { between 0-1 hour } \\
\text { after onset }\end{array}$ & 11.0 & 21.6 & 24.5 & 19.4 & 11.6 & 5.0 & 7.0 \\
\hline eligeble & $\begin{array}{c}\text { transported } \\
\text { between 1-2 hour } \\
\text { after onset }\end{array}$ & 9.6 & 19.8 & 24.0 & 20.2 & 12.7 & 5.7 & 8.0 \\
\hline eligeble & $\begin{array}{c}\text { transported } \\
\text { between 2-3 hour } \\
\text { after onset }\end{array}$ & 8.4 & 18.1 & 21.3 & 20.9 & 13.8 & 6.3 & 9.2 \\
\hline not eligeble & & 3.6 & 6.2 & 12.5 & 8.7 & 31.2 & 15.0 & 22.5 \\
\hline
\end{tabular}

rt-PA: Recombinant tissue-type plasminogen activator, mRS: modified Rankin Scale

Table 1 footnotes

Table1 shows the expected mRS distributions used in the simulation, which is quote from [11].

It is assumed that patient severity varies with patient transport time and eligibility for rt-PA and subsequent endovascular thrombectomy.

\section{Medical and nursing care costs}

Medical costs as well as nursing care costs are included in the cost analysis, since stroke patients are likely

to suffer from post-stroke disability [33]. In Japan, official rates for medical costs and nursing care costs are applied throughout the country. In this study, these costs are estimated based on the expected mRS distribution. First, data for per-patient medical cost is obtained from Japan Stroke Databank (Table 2) [3]. Nursing care services are insured based on patient care needs, which are assigned based on patients' severity.

The care needs are divided into 7 categories (support levels 1 and 2, and care levels 1-5), with care level patients severer than support level patients. Higher levels mean that patients tend to have severer disability 
[34]. In this study, the care needs of the patients (Table 2) and nursing care costs are estimated from Statistics of Medical Care Activities in Public Health Insurance by the Ministry of Labour, Health, and Welfare [35], in accordance with a previous research [33]. The estimated per-year nursing care costs were \$3,092 for Support Level 1, \$5,285 for Support Level 2, \$11,311 for Care Level 1, \$15,288 for Care Level 2, \$22,389 for Care Level 3, \$26,689 for Care Level 4, and \$30,939 for Care Level 5. Hattori et al. (2012) reported that patients at different mRS stages have different utilization rates of nursing care services [36], that is, severe patients are likely to utilize nursing care services. It is assumed that patients utilize nursing care services at the rates shown in Table 2. This process of estimating medical costs and nursing care costs is applied to patients for each transport time window, and per-patient cost expectations are calculated for each of the transport time windows in each scenario. The expected medical costs and nursing care costs are converted to US dollars at the currency exchange rate as of November 21, 2018 and are discounted at 2\% per year [20].

Table 2. Data on costs, care need level, and nursing care utilization rate, and QALY for each mRS stage used in the simulation

\begin{tabular}{|c|c|c|c|c|c|c|c|}
\hline & \multicolumn{7}{|c|}{ mRS stage } \\
\cline { 2 - 8 } & 0 & 1 & 2 & \multicolumn{1}{c|}{3} & \multicolumn{1}{c|}{4} & 5 & 6 \\
\hline $\begin{array}{c}\text { Total medical costs } \\
\text { (\$US) [3] }\end{array}$ & 7,626 & 10,286 & 14,632 & 16,848 & 20,218 & 28,642 & 24,031 \\
\hline Care need level [32] & $\begin{array}{c}\text { No } \\
\text { care }\end{array}$ & $\begin{array}{c}\text { Support } \\
\text { Level1 }\end{array}$ & $\begin{array}{c}\text { Support } \\
\text { Level 2 }\end{array}$ & $\begin{array}{c}\text { Care } \\
\text { Level 1 }\end{array}$ & $\begin{array}{c}\text { Care Level } \\
2 \text { or 3 }\end{array}$ & $\begin{array}{c}\text { Care Level } \\
4 \text { or 5 }\end{array}$ & $\begin{array}{c}\text { No } \\
\text { care }\end{array}$ \\
\hline $\begin{array}{c}\text { The rate at which nursing } \\
\text { care sevices are utilized } \\
(\%) \text { [35] }\end{array}$ & 0 & 26.1 & 91.8 & 98.5 & 100 & 100 & 0 \\
\hline QALYs [35] & 0.89 & 0.797 & 0.65 & 0.588 & 0.363 & 0.092 & 0 \\
\hline
\end{tabular}

Table2 footnotes 
A Cost-effectiveness Simulation of Drive and Retrieve System in Hokkaido

Table2 shows the data on total medical costs [3], care need levels [32], the rates at which nursing care services

[35], and Quality Adjusted Life Years (QALYs) for patients at each mRS stage [35] used in the simulation.

It is assumed that those parameters vary with patient mRS stages.

\section{QALY}

As mentioned above, QALY is used as a measurement of patient outcome. QALY is a standard measurement for health technology assessment. The Ministry of Labor, Health, and Welfare (2016) recommends QALY for evaluating cost effectiveness of medical treatments or services [21]. In this study, QALY data is assigned to patients based on the results of Hattori et al. (Table 2) [36]. The expected QALYs are discounted at 2\% per year [20].

\section{Results}

\section{Patient accessibility}

The estimated number of AIS patients were 8,528, excluding 16 patients in the solitary island areas. Figure

1 shows the rates for patients transported to hospitals with endovascular thrombectomy within 3 hours (covered rate), and the detailed results (e.g. the number of patients in each time window, the covered rates) are shown in Table3. Covered rates were 98.5\% $(8,397)$ for the current scenario, $99.0 \%(8,442)$ for the 60 minute scenario, and 99.1\% $(8,448)$ for the 90-minute scenario. The transport time of 178 and 248 patients would be shortened by the 60-mintute and 90-minute scenario, respectively (these figures are obtained by 
summing the number of patients whose transport time was shortened at each medical area (Table 3)). In 14

of the 21 secondary medical areas, covered rate was $100 \%$ in the current scenario. Currently, approximately

$7.6 \%$ of the patients are transported to hub hospitals within 1 hour in the Kamikawahokubu medical area.

The rate can increase to $85 \%$ with the drive and retrieve system. In Emmon, Kitaoshimahiyama, and

Kamikawahokubu areas, the cover rates would be $100 \%$ in the 60 -minute scenario. In Rumoi area, the

covered rate was $87 \%$ in the current scenario. The number increases to $93 \%$ in the 60 -minute scenario, and

$100 \%$ in the 90 -minute scenario. Soya has the lowest covered rate in the current scenario (1\%). Although

the rate would increase to $25 \%$ and $26 \%$ in the 60 -minute and 90 -minute scenarios, respectively, rt-PA and

endovascular thrombectomy would still not be accessible to a large number of patients. In Hidaka and

Nemuro, $5 \%$ and $2 \%$ of patients would currently not be transported to hub hospitals within 3 hours, and the

rate would not change even in the 90-minute scenario, respectively.

Table 3. The number of patients transported in each time window in each medical area

\begin{tabular}{|c|c|c|c|c|c|c|c|}
\hline \multirow{2}{*}{$\begin{array}{c}\text { Secondary medical } \\
\text { area }\end{array}$} & \multirow[b]{2}{*}{ Scenario } & \multicolumn{5}{|c|}{ Transport Time Window } & \multirow{2}{*}{$\begin{array}{c}\text { Cover } \\
\text { Rate }\end{array}$} \\
\hline & & Total & $\begin{array}{l}0-1 \\
\text { hour }\end{array}$ & $\begin{array}{l}1-2 \\
\text { hour }\end{array}$ & $\begin{array}{l}2-3 \\
\text { hour }\end{array}$ & $\begin{array}{l}\text { over } \\
3 \text { hours }\end{array}$ & \\
\hline All Hokkaido & Current & 8,528 & 7,085 & 8,037 & 8,397 & 131 & $98.5 \%$ \\
\hline All Hokkaido & 60-minute & 8,528 & 7,270 & 8,104 & 8,442 & 86 & $99.0 \%$ \\
\hline All Hokkaido & 90-minute & 8,528 & 7,270 & 8,163 & 8,448 & 80 & $99.1 \%$ \\
\hline Minamioshima & Current & 615 & 555 & 608 & 615 & 0 & $100 \%$ \\
\hline Minamioshima & 60-minute & 615 & 561 & 608 & 615 & 0 & $100 \%$ \\
\hline Minamioshima & 90-minute & 615 & 561 & 615 & 615 & 0 & $100 \%$ \\
\hline Minamihiyama & Current & 26 & 0 & 26 & 26 & 0 & $100 \%$ \\
\hline Minamihiyama & 60-minute & 26 & 0 & 26 & 26 & 0 & $100 \%$ \\
\hline Minamihiyama & 90-minute & 26 & 0 & 26 & 26 & 0 & $100 \%$ \\
\hline Kitaoshimahiyama & Current & 55 & 0 & 30 & 53 & 2 & $96 \%$ \\
\hline
\end{tabular}


A Cost-effectiveness Simulation of Drive and Retrieve System in Hokkaido

\begin{tabular}{|c|c|r|r|r|r|r|r|} 
Kitaoshimahiyama & 60 -minute & 55 & 0 & 36 & 55 & 0 & $100 \%$ \\
\hline Kitaoshimahiyama & 90 -minute & 55 & 0 & 52 & 55 & 0 & $100 \%$ \\
\hline Sapporo & Current & 3,781 & 3,772 & 3,781 & 3,781 & 0 & $100 \%$ \\
\hline Sapporo & 60 -minute & 3,781 & 3,779 & 3,781 & 3,781 & 0 & $100 \%$ \\
\hline Sapporo & 90 -minute & 3,781 & 3,779 & 3,781 & 3,781 & 0 & $100 \%$ \\
\hline Shiribashi & Current & 335 & 200 & 322 & 335 & 0 & $100 \%$ \\
\hline Shiribashi & 60 -minute & 335 & 229 & 331 & 335 & 0 & $100 \%$ \\
\hline Shiribashi & 90 -minute & 335 & 229 & 331 & 335 & 0 & $100 \%$ \\
\hline Minamisorachi & Current & 263 & 241 & 263 & 263 & 0 & $100 \%$ \\
\hline Minamisorachi & 60 -minute & 263 & 242 & 263 & 263 & 0 & $100 \%$ \\
\hline Minamisorachi & 90 -minute & 263 & 242 & 263 & 263 & 0 & $100 \%$ \\
\hline Nakasorachi & Current & 178 & 173 & 178 & 178 & 0 & $100 \%$ \\
\hline Nakasorachi & 60 -minute & 178 & 173 & 178 & 178 & 0 & $100 \%$ \\
\hline Nakasorachi & 90 -minute & 178 & 173 & 178 & 178 & 0 & $100 \%$ \\
\hline Kitasorachi & Current & 53 & 39 & 53 & 53 & 0 & $100 \%$ \\
\hline Kitasorachi & 60 -minute & 53 & 48 & 53 & 53 & 0 & $100 \%$ \\
\hline Kitasorachi & 90 -minute & 53 & 48 & 53 & 53 & 0 & $100 \%$ \\
\hline Nishiiburi & Current & 286 & 278 & 286 & 286 & 0 & $100 \%$ \\
\hline Nishiiburi & 60 -minute & 286 & 283 & 286 & 286 & 0 & $100 \%$ \\
\hline
\end{tabular}

\section{Per-patient medical and nursing care costs}

When calculated considering treatment eligibility and the transfer time windows, the per-patient medical and nursing care costs for patients treated with rt-PA and endovascular thrombectomy were \$36,323 in the 0-1 hour window, $\$ 38,139$ in the $1-2$ hour window, $\$ 39,774$ in the $2-3$ hour window, and $\$ 55,506$ without these treatments. After adjusting these costs with the implementation rate of these treatments, the expected perpatient costs at each transport time window were $\$ 51,852$ in the $0-1$ hour window, $\$ 52,159$ in the $1-2$ hour window, \$52,436 in the 2-3 hour window, and \$55,506 in the over 3 hour window.

\section{Cost-effectiveness of the drive and retrieve system}


A Cost-effectiveness Simulation of Drive and Retrieve System in Hokkaido

ICER after implementing the drive and retrieve system was calculated from the results of patient transport time, per-patient costs, and QALYs for each transport time window. The ICER was dominant, both in the 60-minute and 90-minute scenarios. QALY gain was 7.0 in the 60-minute scenario, and 8.13 in the 90minute scenario. The results showed cost reduction of $\$ 213,190$ in the 60 -minute scenario (Figure 2) and $\$ 247,272$ in the 90-minute scenario (Figure 3). Figure 2 shows the cost reduction in each secondary medical area achieved in the 60 -minute scenario. Cost reduction is the highest in Soya $(\$ 70,433)$, followed by Emmon $(\$ 46,425)$, Kamikawahokubu $(\$ 34,232)$, and Rumoi $(\$ 18,067)$ in the 60 -minute scenario. The reduction for these medical areas accounted for approximately $79 \%$ of the reduction in the whole Hokkaido. Figure 3 shows the cost reduction for each secondary medical area achieved in the 90-minute scenario. In 15 of the 21 medical areas, no change was observed between the results in 60-minute and 90-minute scenarios. In the 90 -minute scenario, Soya area has the largest cost reduction $(\$ 75,149)$, followed by Emmon $(\$ 52,489)$, Rumoi $(\$ 35,033)$, and Kamikawahokubu medical areas $(\$ 34,232)$. Figure 4 shows the per-patient cost reduction. Expected per-patient cost reduction was the highest when the drive and retrieve system was applied to patients in Soya (\$3,062 per case), followed by Emmon (\$1,934 per case), Rumoi (\$1,807 per case), and Kitaoshimahiyama (\$1,296 per case).

\section{Discussion}

The patients in this study were generated based on the incidence and the actual population distribution in each $1 \mathrm{~km}^{2}$ mesh in Hokkaido. Therefore, this distribution is likely to reflect the actual patient distribution. The covered rate was $98.5 \%$ in the current system, which indicates that a large number of patients can be 
A Cost-effectiveness Simulation of Drive and Retrieve System in Hokkaido

eligible for rt-PA and endovascular thrombectomy, especially in the urban areas such as Sapporo,

Kamikawachubu, and Minamihiyama, even in the current scenario. Soya had the lowest rate (1\%),

followed by Rumoi (86\%), and the other 5 areas (Table 3). These medical areas do not have Spoke

hospitals. The results indicate that regional disparity exists in accessibility of patients to these treatments,

which supports previous studies [17], and corporation for AIS treatments among secondary medical areas

is of importance to deliver more equal and efficient treatments. By implementing a 60-minute drive and

retrieve system, the covered rate in Hokkaido would increase to 99.0\%. 178 and 248 patients would benefit

from the system by being transported in a shorter time window (Table 3). Therefore, the drive and retrieve

system can increase equality in access to treatment for ischemic stroke patients, which is can be achieved

using existing medical resources. The cover rate would increase from $1 \%$ to $25 \%$ in Soya, $89 \%$ to $100 \%$ in

Emmon, $87 \%$ to $93 \%$ in Rumoi, and $96 \%$ to $100 \%$ in Kitaoshimahiyama. The results indicate that the

drive and retrieve system within 60-minute drive distance is effective in these medical areas. In

Kamikawahokubu, the rate of patients transported in the $0-1$ hour time window would increase from $7.6 \%$

to $85 \%$. Patients in this medical area can benefit from an early start of treatment. In Rumoi, the covered

rates were $87 \%$, 93\%, and $100 \%$ under the 3 scenarios. The 90 -minute scenario would help in providing

more equal treatment in Rumoi area.

Per-patient expected costs were cheaper, and per-patient expected QALYs were higher with shorter time

windows. This is attributed to better outcomes due to an early start of treatment, which results in less

medical and nursing care costs. The amount of QALY gained was not substantial because in Hokkaido, a 
A Cost-effectiveness Simulation of Drive and Retrieve System in Hokkaido

large part of population can be transported within 3 hours even in the current scenario. However, since the

ICER from implementing the drive and retrieve system was dominant, the system can be a solution to

enhance equality and cost-effectiveness of treatments for patients with AIS.

There were cost reduction effects of the drive and retrieve system. The analysis revealed that cost reduction was high in Soya, Emmon, Rumoi, and Kamikawahokubu. As mentioned above, patients in these medical areas can expect better outcomes through transportation in a shorter time window, and the increase in cover rates. Since the number of neurointerventionists is limited, it is necessary to prioritize the allocation of new human resources in these medical areas.

Per-patient cost reduction is the highest in Soya, followed by Emmon, Rumoi, and Kitaoshimahiyama. More and more patients became eligible for rt-PA and endovascular thrombectomy with this system in these areas. Since high effectiveness of rt-PA and endovascular thrombectomy have been reported [4,5], it is desirable that these treatments are given to as many patients as possible. Even though the increase in the number of patients covered by the system is not substantial, it would be of great importance in providing more equal and cost-effective treatment for patients with ischemic stroke in Hokkaido. Further cost analysis is required from the hospital perspective.

However, this study has several limitations. First, the period of QALY and cost analyses is 3 years due to lack of data. Post-stroke disability is likely to last for a lifetime [32]. Therefore, lifetime analyses with detailed data will give a better assessment of the effects of the drive and retrieve system. Second, due to lack of data, the implementation rate of rt-PA and endovascular thrombectomy is constantly set at $16.9 \%$. 
A Cost-effectiveness Simulation of Drive and Retrieve System in Hokkaido

In a clinical condition, it is possible that the rate varies with transport time, and the implementation rate can improve and change over time. Third, although the results of this study revealed the possible cost reduction brought by implementing the drive and retrieve system, our analysis did not contain public costs to maintain the system that may arise if the system is implemented as a policy (e.g. subsidy for hospitals that manage the system). Lastly, further research is required to apply the drive and retrieve system in a wider area, after considering the availability of the neurointerventionists.

\section{Conclusion}

In this study, the effects of the drive and retrieve system in Hokkaido on patient accessibility to rt-PA and endovascular thrombectomy was analyzed using GIS; and the cost effectiveness of the system was assessed with ICER from the public perspective as a primary outcome, in order to provide data for effective management of ischemic stroke treatments. The results indicated that there were regional disparities in patient accessibility to these treatments. It is possible to reduce disparities using the drive and retrieve system. The cost-effectiveness analysis revealed that the ICER was dominant after implementing this system, and cost reduction would be expected. Therefore, this system can be a solution to achieve more equal and cost-effective treatments. Additionally, the results showed that cost reductions were high in Soya, Emmon, Rumoi, and Kamikawahokubu medical areas. Further analysis from hospital perspective is required to clarify whether the system is cost-effective for involved hospitals.

\section{Acknowledgements}

We would like to thank Editage (www.editage.jp) for English language editing. 
A Cost-effectiveness Simulation of Drive and Retrieve System in Hokkaido

\section{References}

1. The Ministry of Health Labour and Welfare. Comprehensive Survey of Living Conditions 2013, nursing care. Avaiable at https://www.mhlw.go.jp/toukei/list/20-21.html (accessd on September 27, 2018)

2. The Ministry of Health Labour and Welfare. Survey of Long-term Care Benefit Expenditures, 2017. Available at https://www.mhlw.go.jp/toukei/list/45-1.html （accessd on 2018,27 September）

3. Kobayashi H. The Japanese Stroke Databank 2015 Total Medical Fees. Nakayama Shoten.

4. Guidelines for the intravenous application of recombinant tissue-type plasminogen activator (alteplase), the second edition, October 2015: a guideline from the Japan Stroke Society.

5. Guideline for the proper use of mechanical thrombectomy device, the second edition: a guideline from the Japan Stroke Society, the Japan Neurosurgical Society and the Japanese Society for Neuroendovascular Therapy. 2015

6. The National Institute of Neurological Disorders and Stroke rt-PA Stroke Study Group. Tissue plasminogen activator for acute ischemic stroke. N Engl J Med. 1995; 333: 1581-1587

7. Yamaguchi T, Mori E, Minematsu K, et al. Alteplase at $0.6 \mathrm{mg} / \mathrm{kg}$ for acute ischemic stroke within 3 hours of onset: Japan Alteplase Clinical Trial. Stroke. 2006; 37: 1810-1815

8. Toyoda K, Koga M, Naganuma M, et al. Routine use of intravenous low-dose rt-PA in Japanese patients: general outcomes and prognostic factors from the SAMURAI register. Stroke. 2009; 40: 3591-3595

9. Kleindorfer D, Xu Y, Moomaw CJ et al. US geographic distribution of rt-PA utilization by hospital for acute ischemic stroke. Stroke 2009;40: 3580-3584.

10. Okada Y, Minematsu K, Ogawa A. Nation-wide survey of intravenous rt-PA (alteplase) therapy during the first four years after approval For overcoming regional gaps . Jpn J 2010, Stroke 32: 365-372. (in Japanese)

11. Saver Jeffrey L, Goyal Mayank, van der Lugt Aad et al. Time to Treatment With Endovascular Thrombectomy and Outcomes From Ischemic Stroke: A Meta-analysis. JAMA-JOURNAL OF THE AMERICAN MEDICAL ASSOCIATION 2016;316(12)1279-1288.

12. Geospecial Information Authority of Japan. Statistical reports on the land area by prefectures and municipalities in Japan. 2017. Available at http://www.gsi.go.jp/KOKUJYOHO/MENCHO201710- 
A Cost-effectiveness Simulation of Drive and Retrieve System in Hokkaido

index.html (Accessed on September 26, 2018)

13. Hokkaido. Hokkaido Healthcare Plan [revised edition]; 2013. Available at:

http://www.pref.hokkaido.lg.jp/hf/cis/iryokeikaku/00hokkaidouiryokeikaku.htm. (Accessed September 26, 2018)

14. Kazuo Hashi. Present status of intravenous rt-PA therapy and regional difference in its availability in Japan. Jpn J Stroke 2010: 32: 770-772. (in Japanese)

15. Fujiwara Kensuke, Osanai Toshiya, Kobayashi Eiichi et al. Accessibility to Tertiary Stroke Centers in Hokkaido, Japan: Use of Novel Metrics to Assess Acute Stroke Care Quality. Journal of Stroke and Cerebrovascular Diseases 2018; 27:177-184.

16. Sheth KN, Smith EE, Grau-Sepulveda, MV. Drip and ship thrombolytic therapy for acute ischemic stroke use, temporal trends, and outcomes. Stroke 2015; 52:175-180.

17. Milne MS, Jessalyn HK, Hill MD. Drip 'n Ship Versus Mothership for Endovascular Treatment: Modeling the Best Transportation Options for Optimal Outcomes. Stroke 2018; 48:3, 791-794.

18. Osanai T, Ito Y, Ushikoshi S et al. Efficacy of "Drive and Retrieve" as a cooperative method for the prompt endovascular treatment for acute ischemic stroke. J Neurointerv Surg 2019. (in press).

19. Central Social Medical Insurance Council. Establishment of a threshold in health technology assessment 2018. Available at https://www.mhlw.go.jp/file/05-Shingikai-12404000-HokenkyokuIryouka/0000211609.pdf (Accessed on October 17, 2018).

20. National Institute of Health and Care Excellence. The guideline manual. 7 Assessing cost effectiveness. Available at https://www.nice.org.uk/process/pmg6/chapter/assessing-cost-effectiveness (Accessed Octover 17, 2018)

21. Fukuda T, Shiroiwa T, Ikeda S et al., Guideline for economic evaluation of healthcare technologies in Japan. J. Natl. Inst. Public Health 2013;62:625-640.

22. Hokkaido Division of the Japanese Society for Neuro Endovascular Therapy. Specialists in Hokkaido. Available at: http://jsnet.hkdo.jp/. (Accessed June 5, 2017)

23. Ministry of Land, Infrastructure, Transport, and Tourism. National Land Numeral Information Download Service. Available at: http://nlftp.mlit.go.jp/ksj/gmlold/ (Accessed on September 26, 2018) 
A Cost-effectiveness Simulation of Drive and Retrieve System in Hokkaido

24. Goyal M,Menon BK,van Zwam WH,et al. Endovascular thrombectomy after large-vessel ischaemic stroke. Lancet.2016;387(10029):1723-1731

25. Berkhemer OA, Fransen PS, Beumer D, et al. A randomized trial of intraarterial treatment for acute ischemic stroke. N Engl J Med 2015; 372: 11-20.

26. Goyal M, Demchuk AM, Menon BK, et al. Randomized assessment of rapid endovascular treatment of ischemic stroke. N Engl J Med 2015; 372: 1019-30.

27. Saver JL, Goyal M, Bonafe A, et al. Stent-retriever thrombectomy after intravenous t-PA vs. t-PA alone in stroke. N Engl J Med 2015; 372: 2285-95.

28. Campbell BC, Mitchell PJ, Kleinig TJ, et al. Endovascular therapy for ischemic stroke with perfusionimaging selection. N Engl J Med 2015; 372: 1009-18.

29. Jovin TG, Chamorro A, Cobo E, et al. Thrombectomy within 8 hours after symptom onset in ischemic stroke. N Engl J Med 2015; 372: 2296-306.

30. Hacke W, Donnan G, Fieschi C, et al. Association of outcome with early stroke treatment: pooled analysis of ATLANTIS, ECASS, and NINDS rt-PA stroke trials. Lancet. 2004; 363: 768-774.

31. Spokoyny I, Raman R, Ernstrom K et al. Accuracy of first recorded "last known normal”times of stroke code patients. J Stroke Cerebrovasc Dis. .2015;24:2467-2473.

32. STROKE 2013. The epidemiological trend of stroke observed from the Japanese Stroke Databank. 2013. Available at http://att.ebm-library.jp/conferences/2013/stroke/08.html (Accessed on September 26, 2018)

33. Mika Yamaga, Shunya Ikeda. Cost of illness after stroke. Journal of International University of Health and Welfare. 2016, 21: 82-92 (In Japanese)

34. Health and Welfare Bureau for the Elderly, Ministry of Health, Labour and Welfare. Long-Term Care Insurance System of Japan, 2016. Available at https:/www.mhlw.go.jp/english/policy/care-welfare/carewelfare-elderly/dl/ltcisj_e.pdf (accessed on October 17, 2018)

35. Ministry of Health, Labour and Welfare. Statistics of Medical Care Activities in Public Health Insurance 2014. Available at https://www.mhlw.go.jp/toukei/list/45-1.html～（accessd on 2018,27 September) 
A Cost-effectiveness Simulation of Drive and Retrieve System in Hokkaido

36. Hattori N, Hirayama T, Katayama Y. Medical Care for Chronic-Phase Stroke in Japan. 2012, 52: 175180.

\section{Figure Legends}

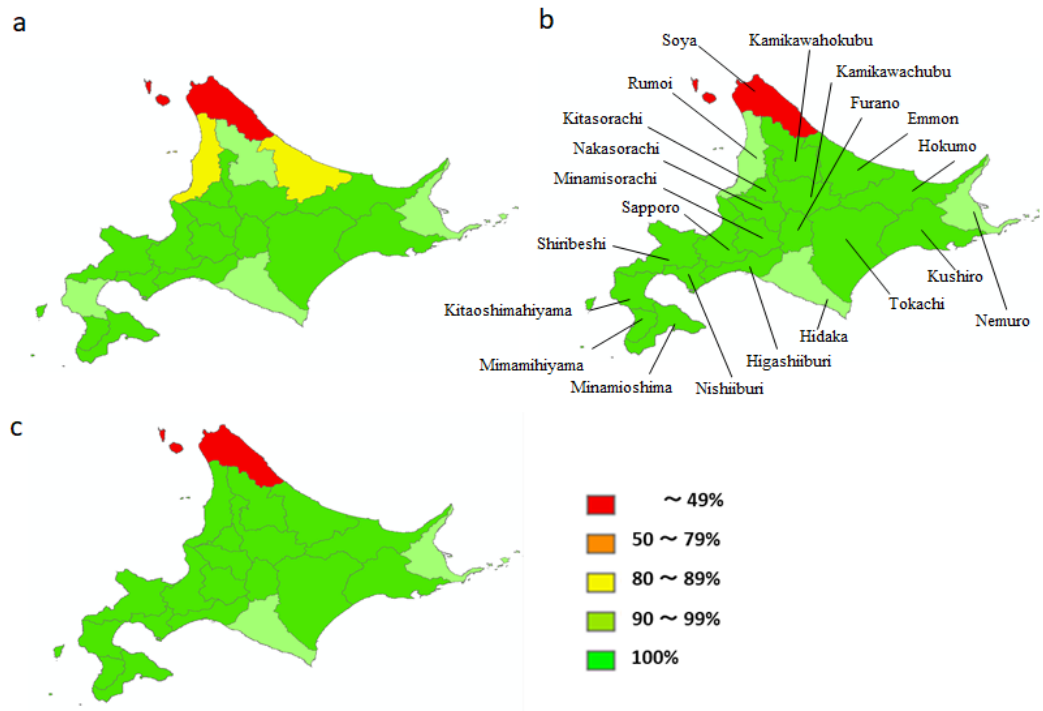

Figure1: Covered rate in each scenario

Figure Legend: The rates of patients whose transport time are within 3 hours (Cover rate) in each scenario

((a) the current scenario, (b) the 60-minute scenario, and (c) the 90-minute scenario) are visualized in Figure

1. The results showed that $100 \%$ cover rate was achieved in 14 of 21 areas in the current scenario. $100 \%$ cover rate would be achieved in the 60-minute drive scenario in Emmon, Kitahitamaoshima, Kamikawahokubu medical areas, in the 90-minutedrive scenario in Rumoi area. In Hidaka and Nemuro medical areas, the cover rates would not change even by implementing the drive and retrieve system. In Soya are, the cover rate would still be $26 \%$ even with the drive and retrieve system. 
A Cost-effectiveness Simulation of Drive and Retrieve System in Hokkaido

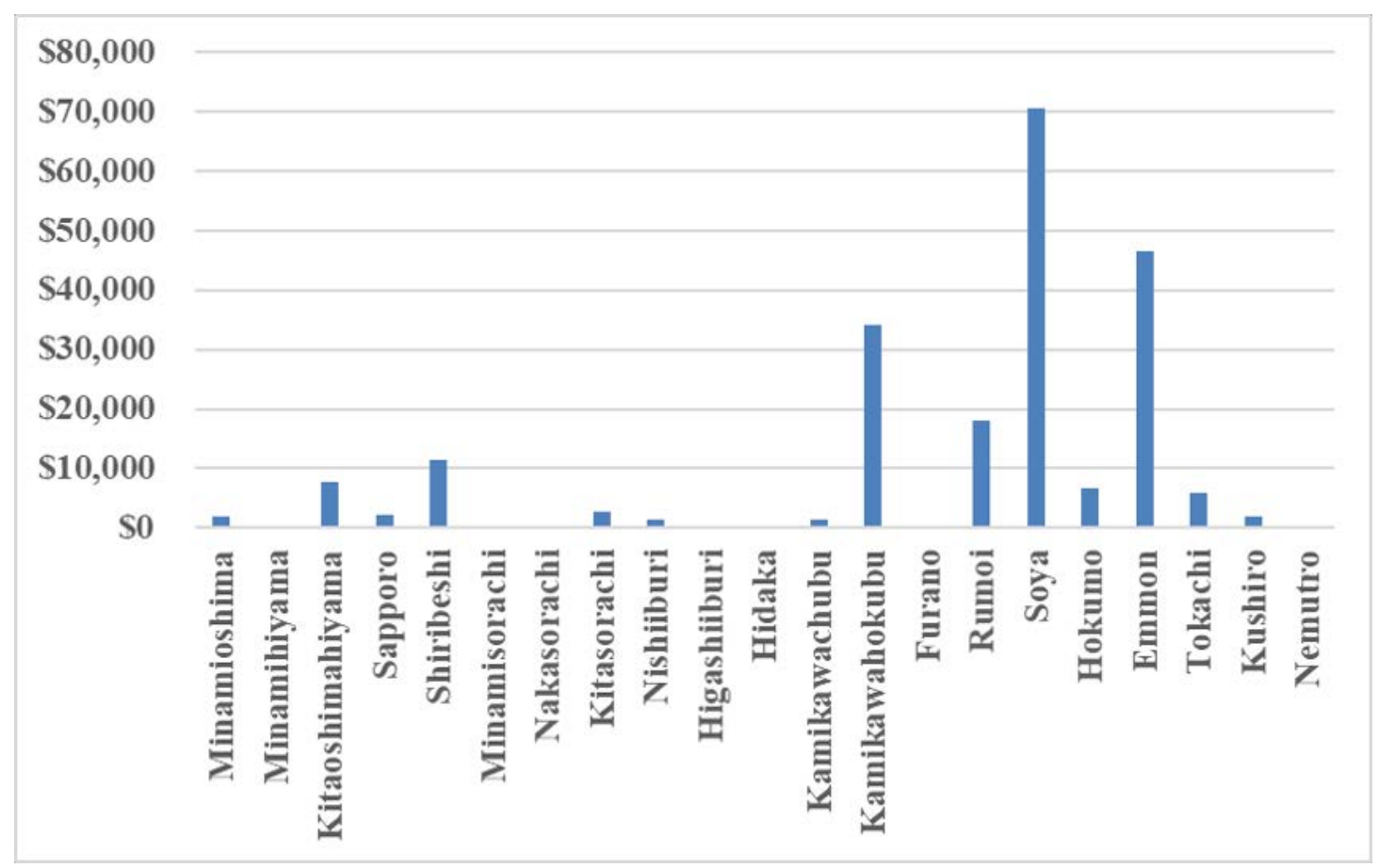

Figure2: The cost reduction in each secondary medical area in 60-minute scenario (\$US)

Figure Legend: Figure 2 shows the cost reduction in each of the secondary medical areas achieved by implementing the 60 -minute drive scenario. The result showed that the total cost reduction was $\$ 213,190$.

Cost reduction is the highest in Soya $(\$ 70,433)$, followed by Emmon $(\$ 46,425)$, Kamikawahokubu $(\$ 34,232)$, and Rumoi $(\$ 18,067)$. 
A Cost-effectiveness Simulation of Drive and Retrieve System in Hokkaido

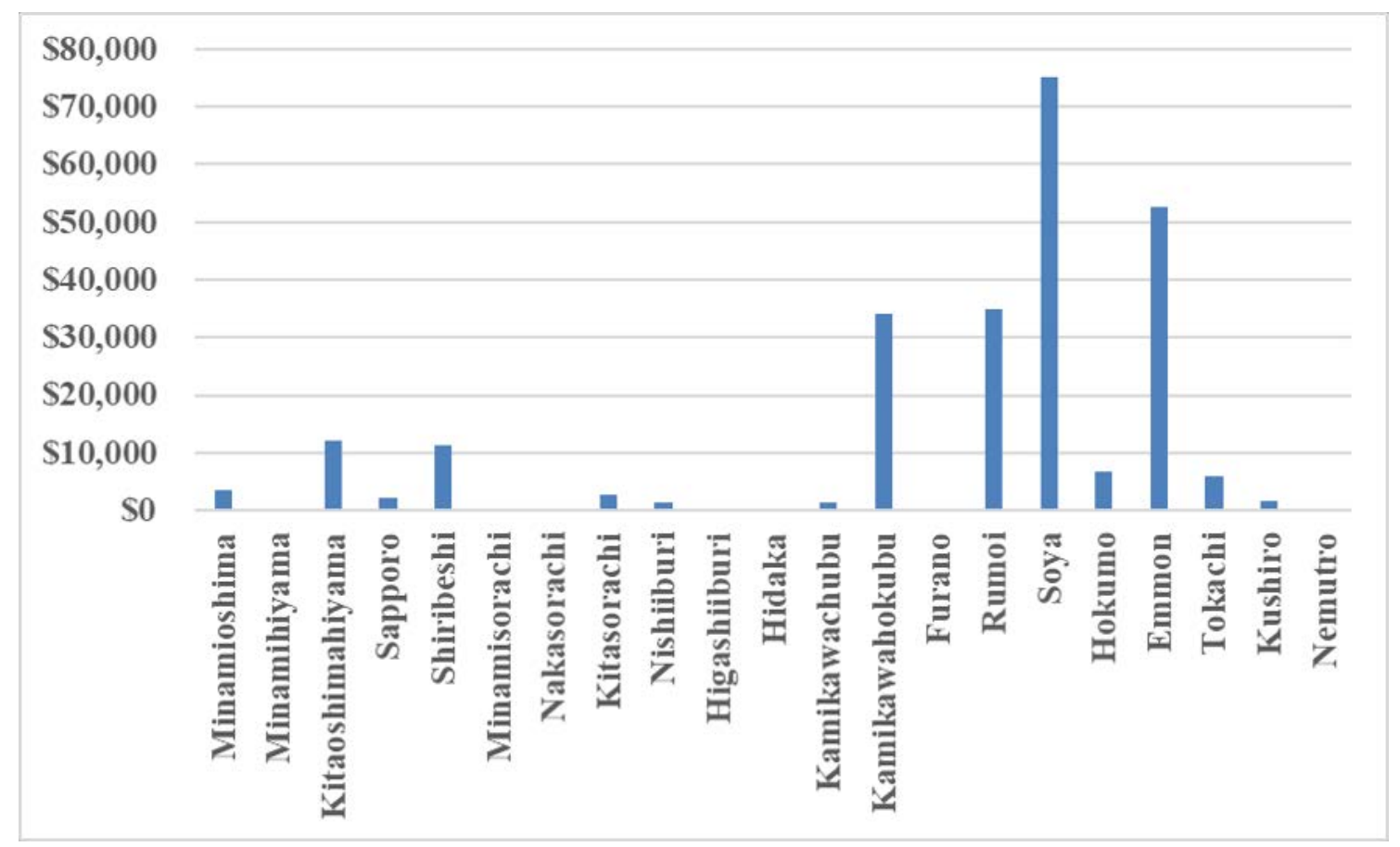

Figure3: The cost reduction in each secondary medical area in 90-minute scenario (\$US)

Figure Legend: Figure 3 shows the cost reduction in each of the secondary medical areas achieved in the 90minute scenario. The result showed that the total cost reduction was $\$ 247,272$. Soya area has the largest cost reduction $(\$ 75,149)$, followed by Emmon $(\$ 52,489)$, Rumoi $(\$ 35,033)$, and Kamikawahokubu medical areas $(\$ 34,232)$. 
A Cost-effectiveness Simulation of Drive and Retrieve System in Hokkaido

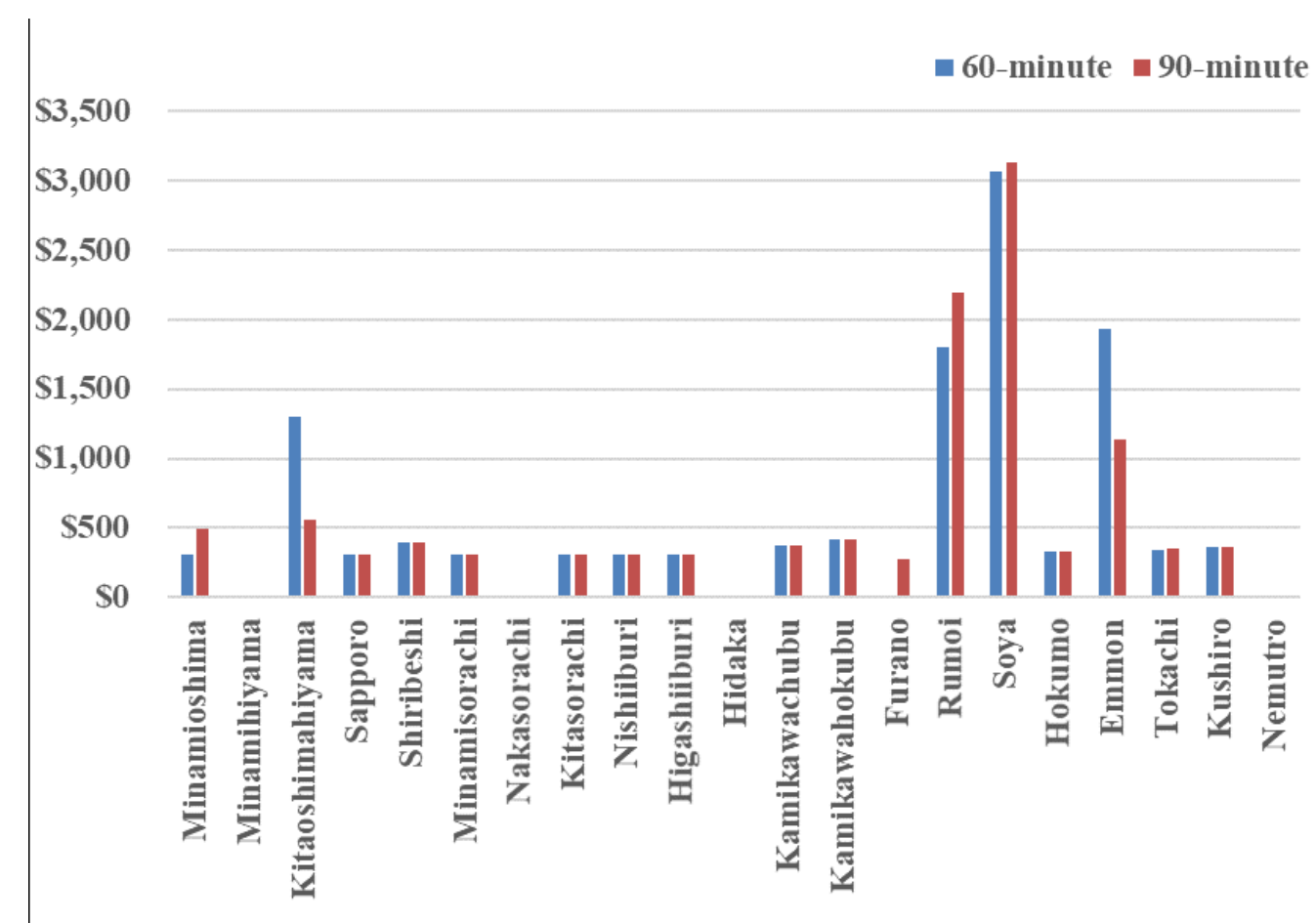

Figure4: the cost reduction gained per 60-minute drive and retrieve system (\$US)

Figure Legend: Figure 4 shows the results of per-patient cost reduction in each secondary medical area, which is calculated by deriving the total cost reduction by the number of patients whose transport time are shorten by 60-minute drive scenario. Per-patient cost reduction was largest in Soya area (\$3,062 per case), followed by Emmon area $(\$ 1,934)$, Rumoi $(\$ 1,807)$, Kitahiyamaoshima $(\$ 1,296)$. 